\title{
Control of cervical cancer in Peru: Current barriers and challenges for the future (Review)
}

\author{
ALFREDO AGUILAR $^{1}$, JOSEPH A. PINTO ${ }^{2}$, JHAJAIRA ARAUJO ${ }^{2}$, WILLIAMS FAJARDO ${ }^{3}$, \\ LENY BRAVO $^{3}$, LUIS PINILLOS ${ }^{4}$ and CARLOS VALLEJOS ${ }^{1}$ \\ ${ }^{1}$ Department of Medical Oncology; ${ }^{2}$ Unit of Basic and Translational Research, Oncosalud-AUNA, \\ San Borja, Lima $41 ;{ }^{3}$ School of Human Medicine, St. John's Private University, Chorrillos, \\ Lima 09; ${ }^{4}$ Department of Radiotherapy, Oncosalud-AUNA, San Borja, Lima 41, Peru
}

Received December 11, 2015; Accepted May 9, 2016

DOI: $10.3892 / \mathrm{mco} .2016 .926$

\begin{abstract}
Cervical cancer is the leading malignant neoplasm in Peruvian women. This malignancy is a public health problem and several efforts were previously performed to develop cancer control plans. Geographical, cultural, structural, infrastructural and procedural barriers can limit the implementation of such strategies. Several previous studies have characterized human papilloma virus (HPV) epidemiology, where prevalence of high-risk HPV in adult females is $\sim 12 \%$ and the prevalence in cervical cancer is $90-95 \%$. The predominant barriers for the control of cervical cancer are lack of specialists in remote villages, education/cultural issues, loss of patients in follow-up, lack of access to HPV testing and lack of compliance for HPV vaccination. A good strategy for the prevention and early detection of high-risk HPV, pre-malignant neoplasms and cervical cancer, identified by interventional studies, is the self-sampling test, which assists with overcoming the cultural and geographic barriers. The current cancer control plan, termed 'Plan Esperanza', is performed with massive training of health professionals and social sensitization campaigns leading to filling the gaps regarding education and, in addition, it provides cancer care coverage for poorer individuals. In our experience at Oncosalud-AUNA, with a cohort of $\sim 750,000$ affiliates using a pre-paid system with annual screenings for cervical cancer for women, offered free-of-charge, a lower incidence of this malignancy $(5.8 / 100,000)$ is now observed compared with the national incidence $(32.7 / 100,000)$. As in other countries, the HPV vaccination can be a cost-utility strategy to reduce the high burdens of cervical cancer in Peru, a rapid and cheap HPV molecular sub-typification is rapidly required.
\end{abstract}

Correspondence to: Dr Carlos Vallejos, Department of Medical Oncology, Oncosalud-AUNA, Avenue Guardia Civil 571, San Borja, Lima 41, Peru

E-mail: cvallejos@oncosalud.pe

Key words: cervical cancer, human papilloma virus, cancer control program

\section{Contents}

1. Cervical cancer in Peru

2. Epidemiology of HPV in Peru

3. Initiatives for cancer control in Peru

4. Barriers for cervical cancer control

5. Approaches to improve the early detection of cervical cancer in Peru

6. Is massive HPV vaccination suitable for the Peruvian population?

7. Challenges for the future

\section{Cervical cancer in Peru}

Cervical cancer is a public health problem predominantly in developing countries where the incidence and mortality rates are high. GLOBOCAN data regarding this malignancy for Peru describe a total of 4,636 novel cases with 1,715 mortalities in 2012 (1). Peru is located on the west coast of South America with $\sim 31$ million inhabitants, where one-third of the total population lives in Lima, the capital city. This concentration of population in only one city contributed to the establishment of structural, infrastructural and procedural barriers for the Peruvian health system.

The cervical cancer incidence varies across the regions in Peru. Geographically, Peru have three well defined regions by the Andean mountains, the coast, and the mountains and the jungle, where the population from each region is exposed to different environmental conditions and risk factors.

With regards to Lima, located in the coast of Peru, data from the Metropolitan Cancer Registry describes a cervical cancer age-standardized rate (ASR) incidence of 19.2 new cases per 100,000 women annually, quite different to the national incidence that is 32.7 new cases per 100,000 women (2). This difference is explained by lifestyles and socio-cultural inequalities between Lima and the other regions of Peru. Notably, decades ago, Lima had a higher incidence of cervical cancer where a progressive decrease through the time was observed, while the incidence of breast cancer continues to increase due to the process of epidemiological transition (Fig. 1). On the other hand, the Cancer Registry of Meteropolitan Lima 
describes different cervical cancer incidences in the different districts of Metropolitan Lima, where the higher income districts have the lowest cervical cancer incidence (2).

With regards to other Peruvian cities, the latest report of the Cancer Registry of Trujillo (located at north) described an incidence ASR of 43.2 new cases per 100,000 women annually in the period 1996-2002, showing a decrease compared with the period 1991-1995 (incidence, 52.4). By contrast, the Cancer Registry of Arequipa (South of Peru) reported an incidence of 43.2 new cases per 100,000 women annually in the period 2004-2007, higher compared with that reported in the period 2002-2003 (35.2) (3,4). Unfortunately, no other cancer registries exist in Peru. The differences in the decrease of cervical cancer incidence in other Peruvian regions compared to Lima highlights disparities in education and access to specialized healthcare services.

Conventional cytology (Pap) and visual inspection following the application of acetic acid or white vinegar (VIA) are currently used in primary screening, while HPV molecular sub-typing is offered only by a few laboratories.

\section{Epidemiology of HPV in Peru}

Although the pathogenic role of HPV16, 18 and 32 is well understood, other subtypes also have a pathogenic role in cervical cancer. A report by Halec et al (5) describes the HPV subtypes $26,53,66,67,68,70,73$ and 82 as the only infectious agents in several cervical cancer samples, indicating their potential carcinogenic role. This fact could estimate the prevalence of carcinogenic HPV. In an analysis of 10,575 cases of invasive cervical cancer, where our country included 770 cases, a frequency of $85 \%$ of samples positive for HPV DNA were reported, and the most common HPV types were $16,18,31,33,35,45,52$ and 58 (91\% of all HPV DNA-positive cases) (6). A time trend study revealed that HPV16 and 18 were the most common in cervical cancer, with not significant changes since 1940 (7). With regards to HPV prevalence in Peru, earlier reports by Santos et al (8) described that in a population of Metropolitan Lima a prevalence of $95.3 \%$ was observed in women with squamous cell carcinoma and in $92.0 \%$ in women with adenocarcinoma/adenosquamous tumors (HPV 16, 18, 31, 52 and 35 were most frequent), while the frequency the HPV infection in healthy women was 17.7 (8). The TATI project (Spanish acronym for 'screening and immediate treatment' of cervix uteri lesions) that screened 5,435 women from the Peruvian jungle (San Martin) in 2001 demonstrated a high-risk HPV frequency of $12.6 \%$ (9), while a recent report evaluating 2,247 samples from screened women aged 17-79 years from urban areas of Iquitos, Cajamarca, Piura, Chiclayo, Lima, Arequipa, Cuzco and Juliaca described a high-risk HPV distribution of 34.5\%. Of these, $82.7 \%$ of cases had single infections and $17.3 \%$ had multiple infections (10). A study by Bautista et al (11) in 1,142 mothers from the social program 'el vaso de leche' of the Surquillo District in the region of Lima found a prevalence of high-risk HPV of $15.2 \%$ (11). With a small sample size of female sex workers ( $\mathrm{n}=87$ ), Montano et al (12) reported a $50.6 \%$ of infection with HPV with a $35.6 \%$ of infection with high-risk HPV, while Brown et al (13) found in 184 female sex workers (18-26 years old) a $65.8 \%$ rate of HPV infection in cervical samples, where $8.3 \%$ of these women also exhibited oral HPV $(12,13)$.

\section{Initiatives for cancer control in Peru}

The cancer control first initiative in Peru was launched 1935 with taxes on ice and refrigerator devices with the aim of collecting money to build the first cancer hospital. This was inaugurated in 1939 offering treatment, predominantly radiotherapy. In 1985, the first policies for cancer control were developed in the Peruvian National Cancer Institute. The first initiative for a massive plan for prevention of gynecological cancer was launched in 1998 for breast and cervical cancer, while in 2000 the first guidelines for cervical cancer prevention, including the use of pap test as screening method and cryotherapy for treatment, were published. In 2002, the Program for Health Promotion and Cancer Control was launched. With regards to the concern about the public health problem that cancer represents, in 2005 the Multisectoral Coalition 'Peru against Cancer', a multi-institutional initiative of Peruvian Institutions with the support of the American Cancer Society, the Union for International Cancer Control, the World Health Organization/Pan American Health Organization and the Washington Cancer Institute was created. This led to the development of the First National Plan for Cancer Control launched in 2006 under the title 'Strategic Plan 2006-2016'. In 2007, a landmark in Latin America was established with the launch of the first Comprehensive National Cancer Control Plan, where treatment of low-income patients was for free (covered by a Comprehensive Health Insurance). This Cancer Control Plan was performed under a strategic plan of 'budget by results', which means more objectives accomplished and more money for funding. In 2012, the current cancer control plan named 'Plan Esperanza' ('Hope Plan' in Spanish) was launched, which also promotes and supports cancer advisory groups; the social promotion of cancer prevention and development of training programs for thousands of health professionals across the country (14). In 2014, the 'Plan Esperanza' provided cervical cancer screening to $>2.3$ million women in Peru (15).

\section{Barriers for cervical cancer control}

In Peru, well-identified geographical, cultural, structural, infrastructural and procedural barriers exist for plans of cervical control cancer. Disparities also exist between the regions, predominantly due to the centralization and concentration of population in the coast. With regards to cultural barriers, fears and concerns remain a problem for the gynecological examination, including the sampling for the pap smear. Medrano et al (16) demonstrated, in a survey of 225 women attending the public clinic in Los Olivos district, that the fear and shame of the examination, neglect to attend to the gynecological control and laziness to take the screening were factors identified for the non-compliance of the cervical cancer screening (16). Support from husbands or partners is also important for individuals to attend their screen (17). There are few trained specialists in cancer screening and this is more evident in remote villages, and educational levels are higher in the coast compared with the mountains and jungle $(18,19)$. 


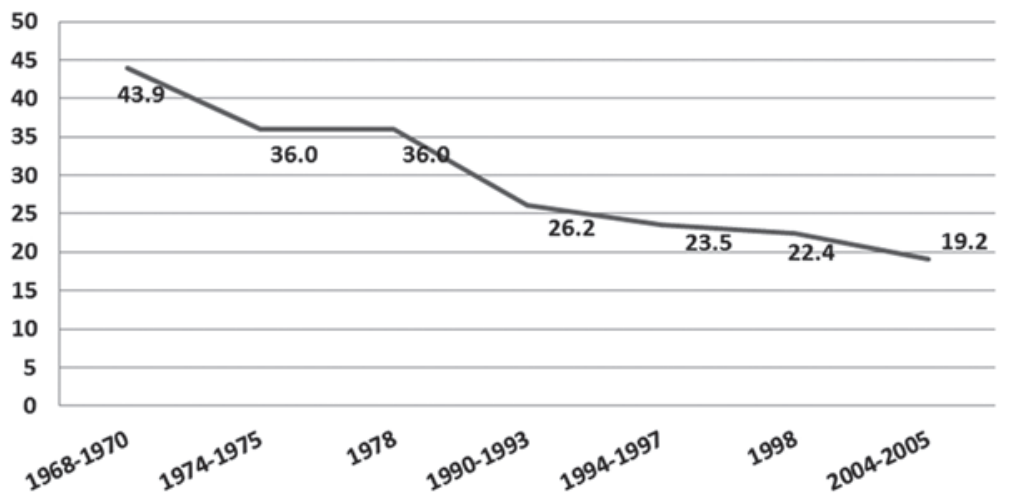

Figure 1. Evolution of cervical cancer incidence in Metropolitan Lima. Age standardized rates of cervical cancer (x100,000 women) are shown. The data was obtained from the Metropolitan Lima Cancer Registry.

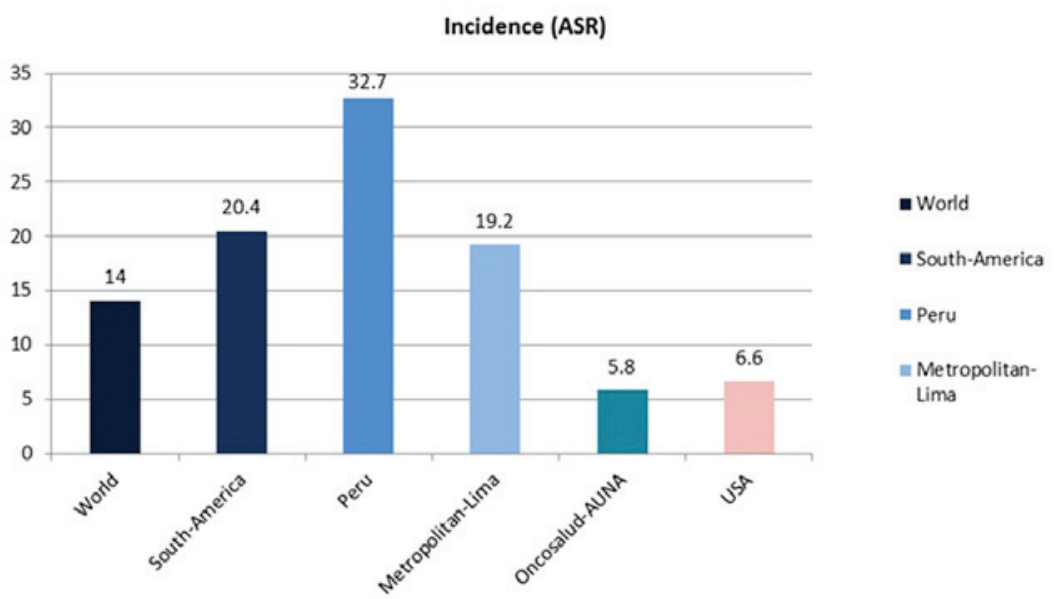

Figure 2. Comparison of cervical cancer incidence worldwide, in South America, Peru, Metropolitan-Lima, USA and a Peruvian Private Institute (Oncosalud-AUNA). The cervical cancer incidence in Oncosalud-AUNA cohort was estimated with 1,478,858.9 individuals - years of follow-up.

A previous study by Paz-Soldan et al (20) in 6,712 women between 18 and 29-years-old in 20 Peruvian cities demonstrated by multivariate analysis that women who are more likely to have a pap smear were those with high levels of education, were married/co-habiting, were at lower age at first intercourse and living by the coast (20).

Since 2007 when the process of decentralization of cancer care was initiated, the current infrastructure is not enough to cover the nationwide demand. A wide gap exists between supply and demand of laboratories, cytopathologists and centers for the management of dysplasias and cancer detection. By contrast, the social structure of remote villages may provide a real barrier to health care intervention at these locations, where leaders of the communities must be identified and involved.

\section{Approaches to improve the early detection of cervical cancer in Peru}

The self-sampling test for molecular prevention of HPV has novel devices with similar sensitivity to a direct endocervical specimen obtained by a physician. This approach is being used in the cervical cancer control strategies, predominantly in locations where cultural factors are identifiable or where there are long distances between the home of patients and the laboratory (or hospital) facilities (21). In a community-based participatory research (CBPR) in the Peruvian Jungle, Abuelo et al (22), described $99.7 \%$ of high satisfaction with the self-sampling for HPV detection, while, $100 \%$ of women invited to be involved $(n=320)$ gave an HPV sample (22). In other community-based participatory research peformed in Manchay, a city near to Lima, it was demonstrated that the health promoters from the community had an important role in the success of the project, where $97 \%$ of registered participants gave an HPV sample and $90 \%$ of women returned for a 6-month follow-up (23).

The insurance coverage appears to be another factor affecting the realization of the pap test. A cross-sectional test by Barrionuevo-Rosas et al (24), in a sample of 12,272 women aged 30-49-years-old demonstrated that women without insurance were the least likely to be screened compared with patients with public insurance (odds ratio $=1.27$; 95\% confidence intervals, 1.24-1.31) and patients with private insurance, (odds ratio $=1.52 ; 95 \%$ confidence intervals, 1.46-1.58) (24).

With regards to high-grade HPV detection, several molecular methods must be evaluated in a cost-effective manner. There is an experience in Peru with self-sampling and solid media specimen cards and with centralized high-throughput processing with MALDI-TOF, where the samples were sent 
to China for analysis and the results were delivered 4 days later (25). This technology must be implemented in strategic regions and can also be cost-effective if laboratories process a great number of samples.

\section{Is massive HPV vaccination suitable for the Peruvian population?}

Vaccination campaigns must also be established with community involvement in order to gain high rates of adherence to cycle dose schedules. In a CBPR, 318 girls from Iquitos (Peruvian jungle) assented for vaccination, 98\% received the first dose of vaccine, 88 and $65 \%$ received the second and third doses, respectively. Completion rates in this study were two times higher than reported in other countries (26). Another interesting strategy is implementation of school-based vaccination programs, which was shown feasible in Peru (27) and where the experience in Brazil demonstrated a three-dose completion rate of $97.2 \%$, with a parental acceptance rate of $91.8 \%$ (28). In addition to these strategies, it is important to develop nationwide programs of formative research to identify and overcome local barriers to developing and performing successfully vaccination programs (29). By contrast, Gutierrez-Aguado (30) demonstrated that in Peru, HPV vaccination can be cost-utility compared with not vaccinating, with an incremental cost-utility of 6775 USD/QALY (30). In 2015, the Ministry of Health planned to vaccinate 475,000 girls (31).

\section{Challenges for the future}

In Peru, it is possible to decrease the incidence of cervical cancer by detecting high-grade HPV and/or intraepithelial cervical neoplasms. Several efforts from the government, Non-governmental organizations and individual researchers have determined the epidemiology and identified several barriers and future challenges to reduce the cervical cancer burden in Peru (Table I).

The case of the Cohort of Oncosalud is interesting. With $\sim 750,000$ affiliates enrolled in a pre-paid system for cancer care (around half are women), the incidence of cervical cancer is 5.8/100,000 women, a lower rate compared with the national incidence $(32.7 / 100,000)$ or the incidence to Metropolitan Lima (19.2/100,000; Fig. 2). The affiliates to Oncosalud are predominantly in the A and B socioeconomic status, and in the context of cancer prevention in this group, screening for free is offered, including mammograms, pap smear and colposcopy for women. By contrast to the low incidence of cervical cancer, a higher incidence compared with the national values is observed in breast cancer (52.7/100,000 vs. $28 / 100,000$ women).

The funding for cancer care is important to improve the outcomes of cervical cancer. In 2014, 64.31\% of patients who attended the National Cancer Institute of Peru were covered by Comprehensive Health Insurance in the context of 'Plan Esperanza' (15). However, the level of coverage for cancer in Lima should improve, since $41 \%$ of the national budget for cervical cancer screening is being spent in Lima, according to the Ministry of Economy and Finances data (32).

Establishment of Cancer Preventoria has provided the infrastructure to empower the screening strategies for the early detection of malignancies, predominantly for breast and cervical cancer. These services should be massively widespread and in addition, the involvement of the mass media in highly important in order to educate the population.

\section{References}

1. Ferlay J, Soerjomataram I, Ervik M, Dikshit R, Eser S, Mathers C, et al: GLOBOCAN 2012 v1.0, cancer incidence and mortality worldwide: IARC Cancer Base No. 11 [Internet]. Lyon, France: International Agency for Research on Cancer; 2013. Available from: http://globocan.iarc.fr, accessed on 01/July/2015.

2. Cancer Registry of Metropolitan Lima, 2014.

3. Albújar PF: Cancer in Trujullo, 1996-2002: Incidence and mortality. Population Cancer Registry of Areguipa, Perú, 2006.

4. Ministerio de Salud: Registro de cáncer poblacional de arequipa, Perú. Arequipa: Instituto Regional de Enfermedades Neoplásicas del Sur, 2011.

5. Halec G, Alemany L, Lloveras B, Schmitt M, Alejo M, Bosch FX, Tous S, Klaustermeier JE, Guimerà N, Grabe N, et al: Pathogenic role of the eight probably/possibly carcinogenic HPV types $26,53,66,67,68,70,73$ and 82 in cervical cancer. J Pathol 234: 441-451, 2014.

6. de Sanjose S, Quint WG, Alemany L, Geraets DT, Klaustermeier JE, Lloveras B, Tous S, Felix A, Bravo LE, Shin HR, et al: Human papillomavirus genotype attribution in invasive cervical cancer: A retrospective cross-sectional worldwide study. Lancet Oncol 11: 1048-1056, 2010.

7. Alemany L, de Sanjosé S, Tous S, Quint W, Vallejos C, Shin HR, Bravo LE, Alonso $\mathrm{P}$, Lima MA, Guimerà $\mathrm{N}$, et al: Time trends of human papillomavirus types in invasive cervical cancer, from 1940 to 2007. Int J Cancer 135: 88-95, 2014.

8. Santos C, Muñoz N, Klug S, Almonte M, Guerrero I, Alvarez M, Velarde C, Galdos O, Castillo M, Walboomers J, et al: HPV types and cofactors causing cervical cancer in Peru. Br J Cancer 85: 966-971, 2001.

9. Almonte M, Ferreccio C, Gonzales M, Delgado JM, Buckley CH, Luciani S, Robles SC, Winkler JL, Tsu VD, Jeronimo J, et al: Risk factors for high-risk human papillomavirus infection and cofactors for high-grade cervical disease in Peru. Int J Gynecol Cancer 21: 1654-1663, 2011.

10. Iwasaki R, Galvez-Philpott F, Arias-Stella J Jr and Arias-Stella J: Prevalence of high-risk human papillomavirus by cobas 4800 HPV test in urban Peru. Braz J Infect Dis 18: 469-472, 2014.

11. Bautista F, Vallejos C, Bances G, Galdos O and Santos C: Prevalence ofcervical and HPV infection in women of the "Milk Glass" comitee in Surquillo District. Carcinos 1: 3-9, 2013.

12. Montano SM, Hsieh EJ, Calderón M, Ton TG, Quijano E, Solari V and Zunt JR: Human papillomavirus infection in female sex workers in Lima, Peru. Sex Transm Infect 87: 81-82, 2011.

13. Brown B, Blas MM, Cabral A, Carcamo C, Gravitt PE and Halsey N: Oral sex practices, oral human papillomavirus and correlations between oral and cervical human papillomavirus prevalence among female sex workers in Lima, Peru. Int J STD AIDS 22: 655-658, 2011.

14. Vallejos C: National plan for prevention, early detection, and cancer control in Peru. Am Soc Clin Oncol Educ Book, 2013.

15. National Cancer Institute of Peru. Main results of 'Hope Plan' 2014. http://www.inen.sld.pe/portal/documentos/pdf/institucional/Memoria/19052015_PRINCIPALES\%20RESUL\%20\% 20DEL\%20INEN\%20\%20PARA\%20PLAN\%20ESPERANZA\% 20Diciembre\%202014\%2020012015.pdf. Accessed August 11, 2015.

16. Medrano MM: Sociocultural and psychological factors that influence the decision of users for taking Pap smear. Carlos Cueto Fernandini health center . Year 2014. Thesis. Faculty of Obstetrics. Universidad Nacional Mayor de San Marcos.

17. Winkler JL, Lewis K, Del Aguila R, Gonzales M, Delgado JM, Tsu VD and Sellors JW: Is magnification necessary to confirm visual inspection of cervical abnormalities? A randomized trial in Peru. Rev Panam Salud Publica 23: 1-6, 2008.

18. Zevallos L, Pastor R and Moscoso B: Supply and demand of medical specialists in the health facilities of the ministry of health: National, regional and by type of specialty gaps. Rev Peru Med Exp Salud Publica 28: 177-185, 2011 (In Spanish).

19. Elias M and Rey S: Educational performance and spatial convergence in Peru. Région et Développement 33: 107-135, 2011. 
20. Paz Soldan VA, Lee FH, Carcamo C, Holmes KK, Garnett GP and Garcia P: Who is getting Pap smears in urban Peru? Int J Epidemiol 37: 862-869, 2008

21. Belinson JL, Du H, Yang B, Wu R, Belinson SE, Qu X, Pretorius RG, Yi X and Castle PE: Improved sensitivity of vaginal self-collection and high-risk human papillomavirus testing. Int J Cancer 130: 1855-1860, 2012.

22. Abuelo CE, Levinson KL, Salmeron J, Sologuren CV, Fernandez MJ and Belinson JL: The Peru cervical cancer screening study (PERCAPS): The design and implementation of a mother/daughter screen, treat, and vaccinate program in the Peruvian jungle. J Community Health 39: 409-415, 2014.

23. Levinson KL, Abuelo C, Chyung E, Salmeron J, Belinson SE, Sologuren CV, Ortiz CS, Vallejos MJ and Belinson JL: The Peru cervical cancer prevention study (PERCAPS): Community-based participatory research in Manchay, Peru. Int J Gynecol Cancer 23: 141-147, 2013.

24. Barrionuevo-Rosas L, Palència L and Borrell C: How does type of health insurance affect receipt of Pap testing in Peru? Rev Panam Salud Publica 34: 393-400, 2013 (In Spanish).

25. Levinson KL, Abuelo C, Salmeron J, Chyung E, Zou J, Belinson SE, Wang G, Ortiz CS, Vallejos CS and Belinson JL: The Peru cervical cancer prevention study (PERCAPS): The technology to make screening accessible. Gynecol Oncol 129: 318-323, 2013.

26. Widdice LE, Bernstein DI, Leonard AC, Marsolo KA and Kahn JA: Adherence to the HPV vaccine dosing intervals and factors associated with completion of 3 doses. Pediatrics 127 : $77-84,2011$.
27. Penny M, Bartolini R, Mosqueira NR, LaMontagne DS, Mendoza MA, Ramos I, Winkler JL, Villafana J, Janmohamed A and Jumaan AO: Strategies to vaccinate against cancer of the cervix: Feasibility of a school-based HPV vaccination program in Peru. Vaccine 29: 5022-5030, 2011.

28. Fregnani JH, Carvalho AL, Eluf-Neto J, Ribeiro Kde C, Kuil Lde M, da Silva TA, Rodrigues SL, Mauad EC, Longatto-Filho A and Villa LL: A school-based human papillomavirus vaccination program in barretos, Brazil: Final results of a demonstrative study. PLoS One 8: e62647, 2013.

29. Bartolini RM, Winkler JL, Penny ME and LaMontagne DS: Parental acceptance of HPV vaccine in Peru: A decision framework. PLoS One 7: e48017, 2012.

30. Gutiérrez-Aguado A: Cost-utility of the vaccine against the human papiloma virus in peruvian women. Rev Peru Med Exp Salud Publica 28: 416-425, 2011 (In Spanish).

31. Ministry of Health of Peru. Press Note. http://www.minsa.gob. pe/?op=51\&nota $=16252$. Accessed August 5, 2015 .

32. Ministry of Economy and Finance of Peru. Economic transparency. http: // apps5.mineco.gob.pe / transparency / Browser / Navegar.aspx. Accessed March 11, 2016. 